\title{
Revisit to Dissection in Ent and its Impact on Students
}

\author{
KC Prasad ${ }^{1 *}$ and Hima Varshini $\mathrm{L}^{2}$ \\ ${ }^{1}$ Department of otorhinolaryngology and head and neck surgery, Sri Devraj Urs Medical College, India \\ ${ }^{2}$ Under Graduate, Sri Devraj Urs Medical College, India
}

Submission: November 21, 2018; Published: December 13, 2018

*Corresponding author: KC Prasad, Professor, Department of otorhinolaryngology and head and neck surgery, Sri Devraj Urs Medical College, kolar, Karnataka, India

Keywords: Temporal bone; Nose and Para nasal sinus; Dissection; Microscope guided; Questionnaire; Understanding

\section{Introduction}

Cadaveric dissection of Temporal bone and nose \& para nasal sinuses held during the otorhinolaryngology and head \& neck surgery postings had a good impact on the student's understanding and orientation to the subject. Despite the advent of modern technology and evolving teaching methods cadaveric dissection continues to remain a corner stone of anatomy curriculum [1].
The students were not exposed to the microscope guided dissection of temporal bone, Para nasal sinuses and the surrounding structures during their course in Anatomy. Learning about ear and paranasal sinuses back then was more through two dimensional pictures from the books and various atlases. But during our clinical postings we were given the chance to watch microscopic guided cadaveric dissection of temporal bone which was performed by our head of the unit.

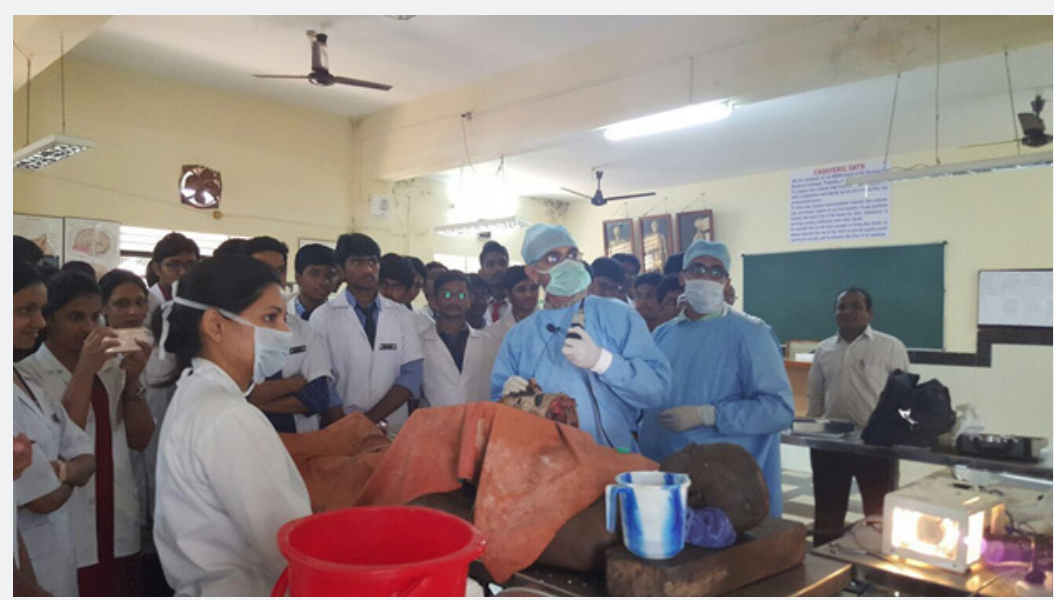

Figure 1: pre-operative image of the large supraclavicular mass.

We got the opportunity of learning the shape and orientation of the structures of temporal bone. Starting from the external ear, tympanic membrane, middle ear ossicles, oval and round windows, intra temporal course of facial nerve, chorda tympani nerve, muscles like tensor tympani and stapedius muscle, mastoid, inner ear structures like semicircular canals cochlea were all clearly shown and explained by our professor. He also explained us certain surgical procedures with the indications, contraindications and complications of the procedures. During the endoscope guided nose and paranasal sinus dissection we were explained the anatomy of turbinate's, meatuses, ethmoidal and maxillary sinuses, cavernous sinus, internal carotid artery and the related surgical procedures. When we went through the textbook following the session, there was easy and clear understanding.

In our discussion session, which was held by another teacher in order to have an unbiased result, the students who 
had attended the session had answered better than those who had not. Though some of the students had answered, they could not answer the deeper questions to which the students who had attended answered. So, the students who had not attended the session felt the need of dissection and had asked for a repeat session. In the repeat session all the students irrespective of the phase were allowed and shared the knowledge.

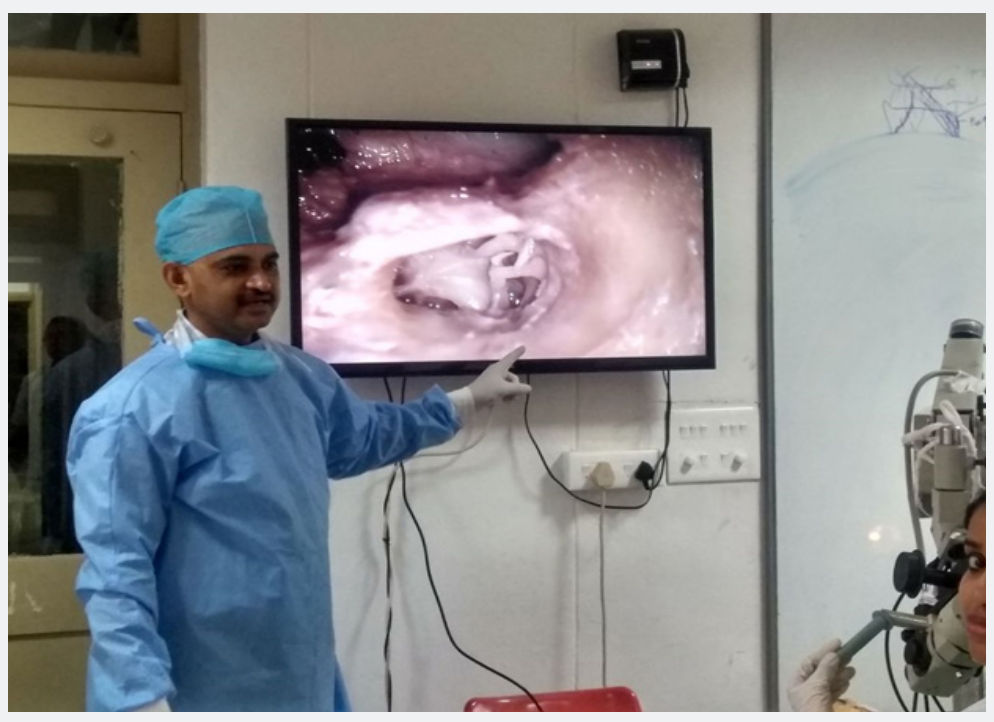

Figure 2: Showing middle ear anatomy explanation.

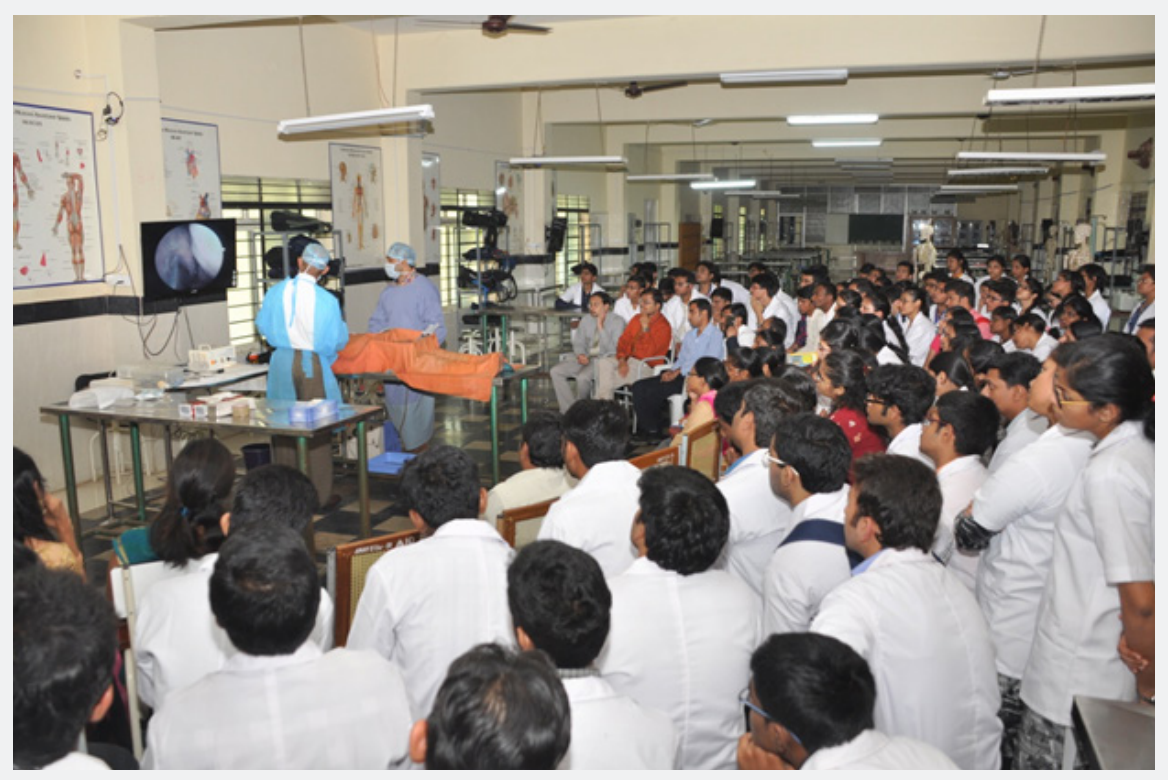

Figure 3: showing under graduates watching the microscope guided dissection.

Dissection gave a better view of structures compared to surgical procedures as the structures obstructing the view can be removed in dissection.

From the student's perspective dissection makes anatomy more interesting and long-lasting knowledge [2] thorough knowledge of anatomy is required for us to understand the pathophysiology of various disorders involving temporal bone and paranasal sinuses and head and neck areas elicit proper history, proper methodological examination, to arrive at clinical diagnosis and for treatment aspect of diseases. So, these dissection sections during our clinical postings deepen our understanding of anatomy and provide three-dimensional perspective of structures thereby improving our skills in history taking clinical examination and understanding surgical procedures [2]. We also performed well in the subsequent internal examination (Figure 1-3).

Students opinion is taken in the form of a feedback questionnaire and the result is as follows.

\section{Result}

i. $\quad 68.2$ percent of the students strongly agree that cadaveric dissection is interesting. 
ii. 59.1 percent of the students strongly agree that knowledge of the temporal bone anatomy helps in clinical posting.

iii. 54.5 percent students disagreed, and 36.4 percent students strongly disagreed that cadaveric dissection is more difficult than textbook anatomy.

iv. 40.9 percent of students strongly agreed, and 45.5 percent of students agreed that teaching of clinical correlation where ever relevant is been done in dissection session.

v. $\quad 54.5$ percent of students strongly agreed, and 45.5 percent of students agreed that flow of dissection clearly explained the content which helped them to understand the anatomy well.

vi. $\quad 68.2$ percent students strongly agreed that explanation given to clarify the temporal bone contents is satisfactory.

vii. 77.3 percent of students strongly agreed that the teacher had encouraged students to ask questions and give answers during dissection. viii. 63.6 percent students strongly agreed that demonstrations were in a way that stimulated interest in the subject.

ix. $\quad 40.9$ percent students strongly agreed and 31.8 percent of them agreed that assessment conducted in the form of written examinations served the purpose to make them aware of their grasp of the subject.

x. $\quad 40.9$ percent of the students agreed, and 36.4 percent of the students strongly agreed assessment conducted in the form of viva voce helped them to improve their subject knowledge application and skills.

Students are looking forward for more dissection classes. Microscopic dissection if made part of the curriculum more students can be benefitted.

\section{References}

1. Ghosh SK (2017) Cadaveric dissection as an educational tool for anatomical sciences in the 21st century. Anat Sci Educ 10(3): 286-299.

2. Dissabandara LO, Nirthanan SN, Khoo TK, Tedman R (2015) Role of cadaveric dissections in modern medical curricula: a study on student perceptions. Anat Cell Biol 48(3): 205-212. 